\title{
A longitudinal magnetic resonance imaging study of neurodegenerative and small vessel disease, and clinical cognitive trajectories in non demented patients with transient ischemic attack: the PREVENT study
}

Sana Tariq ${ }^{1,2,4}$, Christopher D. d'Esterre 1,4, Tolulope T. Sajobi, ${ }^{2,3}$, Eric E. Smith ${ }^{1,2,4}$, Richard Stewart Longman ${ }^{4}$, Richard Frayne ${ }^{2,4,5}$, Shelagh B. Coutts ${ }^{1,3,2,4}$, Nils D. Forkert ${ }^{2,4,5}$ and Philip A. Barber ${ }^{1,2,4^{*}}$ (D)

\begin{abstract}
Background: Late-life cognitive decline, caused by progressive neuronal loss leading to brain atrophy years before symptoms are detected, is expected to double in Canada over the next two decades. Cognitive impairment in late life is attributed to vascular and lifestyle related risk factors in mid-life in a substantial proportion of cases (50\%), thereby providing an opportunity for effective prevention of cognitive decline if incipient disease is detected earlier. Patients presenting with transient ischemic attack (TIA) commonly display some degree of cognitive impairment and are at a 4-fold increased risk of dementia. In the Predementia Neuroimaging of Transient Ischemic Attack (PREVENT) study, we will address what disease processes (i.e., Alzheimer's vs. vascular disease) lead to neurodegeneration, brain atrophy, and cognitive decline, and whether imaging measurements of brain iron accumulation using quantitative susceptibility mapping predicts subsequent brain atrophy and cognitive decline.

Methods: A total of 440 subjects will be recruited for this study with 220 healthy subjects and 220 TIA patients. Early Alzheimer's pathology will be determined by cerebrospinal fluid samples (including tau, a marker of neuronal injury, and amyloid $\beta_{1-42}$ ) and by MR measurements of iron accumulation, a marker for Alzheimer's-related neurodegeneration. Small vessel disease will be identified by changes in white matter lesion volume. Predictors of advanced rates of cerebral and hippocampal atrophy at 1 and 3 years will include in vivo Alzheimer's disease pathology markers, and MRI measurements of brain iron accumulation and small vessel disease. Clinical and cognitive function will be assessed annually post-baseline for a period of 5-years using a clinical questionnaire and a battery of neuropsychological tests, respectively.

(Continued on next page)
\end{abstract}

* Correspondence: pabarber@ucalgary.ca

${ }^{1}$ Calgary Stroke Program, Department of Clinical Neurosciences, Foothills

Medical Centre, 1403 - 29 Street NW, Calgary, AB, Canada

${ }^{2}$ Seaman Family MR Center, Foothills Medical Centre, 1403 29th Street NW,

Calgary, AB, Canada

Full list of author information is available at the end of the article

(c) The Author(s). 2018 Open Access This article is distributed under the terms of the Creative Commons Attribution 4.0 International License (http://creativecommons.org/licenses/by/4.0/) which permits unrestricted use, distribution, and reproduction in any medium, provided you give appropriate credit to the original author(s) and the source, provide a link to the Creative Commons license, and indicate if changes were made. The Creative Commons Public Domain Dedication waiver (http://creativecommons.org/publicdomain/zero/1.0/) applies to the data made available in this article, unless otherwise stated. 


\begin{abstract}
(Continued from previous page)
Discussion: The PREVENT study expects to demonstrate that TIA patients have increased early progressive rates of cerebral brain atrophy after TIA, before cognitive decline can be clinically detected. By developing and optimizing high-level machine learning models based on clinical data, image-based (quantitative susceptibility mapping, regional brain, and white matter lesion volumes) features, and cerebrospinal fluid biomarkers, PREVENT will provide a timely opportunity to identify individuals at greatest risk of late-life cognitive decline early in the course of disease, supporting future therapeutic strategies for the promotion of healthy aging.
\end{abstract}

Keywords: Magnetic resonance imaging, Neurodegeneration, Alzheimer's disease, Vascular dementia, Small vessel disease, Cognition, Aging

\section{Background}

Cognitive impairment late in life is commonly caused by progressive neuronal loss related to two dominant diseases, Alzheimer's disease (AD) and small vessel cerebrovascular disease (i.e. vascular dementia; $\mathrm{VaD}$ ), both causing brain atrophy years before clinical symptoms are detected. As dementia is attributed to vascular and life-style related risk factors in mid-life in a substantial proportion of patients (50\%), there is an opportunity to modify these factors if incipient disease is detected earlier [1]. Transient ischemic attack (TIA; incidence 0.371.1 per 1000) $[2,3]$, is associated with a 4-fold increase in dementia over the general population [4-6]. Therefore, TIA patients are a potential target for early modification of incipient disease processes that precede cognitive impairment guided by biologically relevant markers such as amyloid beta 1-42/ tau, whole brain and sub-structure atrophy, small vessel disease markers, and increased free iron. The Predementia Neuroimaging of Transient Ischemic Attack (PREVENT) study will focus on quantifying these biomarkers using advanced serial magnetic resonance imaging (MRI), neuropsychological assessments, APOE genotyping, and longitudinal clinical data. Specifically, PREVENT will examine what combination of pathological processes and risk factors lead to cognitive decline after TIA.

\section{Methods}

PREVENT is a prospective, single-center longitudinal study. To achieve a 30\% group effect size on annualized rates of cerebral brain atrophy, $N=220$ TIA patients and $N=220$ healthy controls will receive clinical, neuropsychological, fluid biomarker, and MR assessments at pre-specified time points. The frequency and duration of events is summarized in Table 1.

\section{Patient and control subject populations}

The inclusion criteria for the TIA patient cohort are: 1) First documented TIA as defined by the following: resolved symptoms attributable to the anterior circulation (motor, speech, monocular visual loss), or posterior circulation (two or more of: ataxia, diplopia, vertigo, hemi-weakness, hemianopia) [2]; 2) no dementia as defined by National Institute of Aging-Alzheimer Association Criteria [7]; 3) clinical brain MR within 10 days of TIA symptoms to determine presence of diffusion-weighted image (DWI) lesion; 4) an age range between 45 and 75 years; and 5) fluency in English language.

Patient exclusion criteria are as follows: 1) persistence of stroke symptoms $>24 \mathrm{~h}$ [2]; 2) dementia as defined by the National Institute of Aging-Alzheimer Association Criteria [7]; 3) other central nervous system disease (e.g. MS), alcoholism, substance abuse, sedatives, antipsychotic medications and history of psychiatric illness; 4) contraindication to MR imaging, and other comorbidities that could significantly interfere with cognitive performance and follow-up (e.g., recent coronary artery bypass surgery (within 6 months), severe ischemic heart disease, heart failure, poorly controlled diabetes, renal or liver failure etc.).

Healthy controls will include volunteers from the community, and spouses of patients. Exclusion to participation includes prior stroke or TIA, dementia, co-morbid disease etc. as per patient exclusion criteria.

\section{Data collection}

Baseline evaluation (time point: Year 0; Y0) will include clinical review, fasting cholesterol, glucose, and renal function tests. Treatments for hypertension, diabetes, hyperlipidemia, anti-thrombotic agents, and other medications that could influence cognition such as sedatives, anxiolytics, or psychotropic medications will be determined. Apolipoprotein E (APOE) genotyping will be performed; the APOE $\varepsilon 4$ allele is a risk factor for AD and $\mathrm{VaD}$ [8]. Obstructive sleep apnea may affect cognition and will be screened [9]. Blood pressure (BP) measurement will include two sitting BP measurements taken 5 minutes apart. At enrollment, patients and healthy controls will have home BP monitoring training and will perform three readings per day (waking, mid-morning, and evening) with a Bluetooth enabled, telemetric 
Table 1 Schedule of Events

\begin{tabular}{|c|c|c|c|c|c|}
\hline Visit Name & Baseline & Month 12 & Year 3 & Annual Review & Interim Review \\
\hline Inclusion and Exclusion Criteria & $\cdot$ & & & & \\
\hline Medical History, Physical Exam & $\cdot$ & $\cdot$ & $\cdot$ & $\cdot$ & \\
\hline Vital (BP, Heart rate etc.,) Signs & $\cdot$ & $\cdot$ & $\cdot$ & $\cdot$ & \\
\hline DNA Sample Collection for APOE & $\cdot$ & & & & \\
\hline Neuropsychological assessment & & $\cdot$ & $\cdot$ & · & \\
\hline Activities of Daily Living (FAQ) & & $\cdot$ & • & $\cdot$ & \\
\hline Plasma and Serum Biomarker Collection & $\cdot$ & $\cdot$ & $\cdot$ & $\cdot$ & \\
\hline Concomitant Medications & · & $\cdot$ & • & $\cdot$ & $\cdot$ \\
\hline Adverse Events & $\cdot$ & $\cdot$ & $\cdot$ & · & $\cdot$ \\
\hline 3 T MRI Imaging (100\%) & $\cdot$ & $\cdot$ & • & & \\
\hline CSF Collection by Lumbar Puncture & - & & & & \\
\hline
\end{tabular}

system (A\&D Model UA 767BT) during the first month of recruitment [10]. All TIA patients will be managed according to current stroke prevention guidelines [11]. Cerebrospinal fluid (CSF) for AD biomarkers, amyloid $\beta_{1-42}$ and tau, will be collected according to a standardized procedure $[12,13]$. The PREVENT study consent informs the participant that all results from biological tests (i.e. APOE) will not be disclosed to the patient or to the patient's general practitioner. Participants will be approached about brain donation.

\section{Imaging acquisition}

At study entry (Y0) patients will have MR scan as a standard of clinical care within 1-2 days of physician assessment, and then repeated at 1 (Y1) and 3 years (Y3). Healthy controls will have MR scan at the same time points (Y0, Y1, Y3). DWI will be performed to detect evidence of diffusion lesion after TIA (up to 30\%) [14]. The pertinent biological imaging targets of the standard MR imaging acquisition are summarized in Table 2. The absolute brain and hippocampal volume change between
Y0, Y1, and Y3 will be calculated from T1-weighted images with SIENA [15] and FIRST [16, 17] part of FSL software package [18, 19]. At baseline and follow up, FLAIR images will be registered to high-resolution T1 images using a rigid transformation and optimization of the mutual information. Quantitative Susceptibility Mapping (QSM) measurements of regional brain iron accumulation will be acquired using methodology developed and published by the Calgary Image Processing and Analysis Center (CIPAC) [20].

\section{Neuropsychological assessment}

Performed at baseline (within 10 days of onset in TIA patient) and then annually by a trained research assistant (Table 3). The cognitive tests are designed to measure change over time, have been selected to minimize floor and ceiling effects, can distinguish normal aging from prodromal dementia, and will be rotated to reduce practice effects. These tests are consistent with harmonization standards for vascular cognitive impairment (VCI) [21].

Table 2 PREVENT imaging comprehensive dementia protocol $<20$ min of scan time

\begin{tabular}{|c|c|c|c|c|}
\hline Imaging Sequence & Mechanistic Target & Endpoint & $\begin{array}{l}\text { Geometric Parameters (2D/3D, } \\
\text { FOV) }\end{array}$ & $\begin{array}{l}\text { Acquisition Parameters (TE/TR/ } \\
\text { flip) }\end{array}$ \\
\hline 3-plane localizer & & & $\begin{array}{l}2 \mathrm{D}, 24 \mathrm{~cm}, 8 \mathrm{~mm} / 8 \mathrm{~mm}, 33,256 \times \\
128\end{array}$ & $1.3 \mathrm{~ms} / 4.8 \mathrm{~ms} / 30^{\circ}$ \\
\hline $\begin{array}{l}\text { High Resolution T1- } \\
\text { weighted }\end{array}$ & Atrophy & $\begin{array}{l}\text { Primary and secondary } \\
\text { outcome }\end{array}$ & $\begin{array}{l}3 \mathrm{D}, 24 \mathrm{~cm}^{2} 2.0 \mathrm{~mm} / 0 \mathrm{~mm}, 70 \\
256 \times 256\end{array}$ & $\begin{array}{l}3 \mathrm{~ms} / 7 \mathrm{~ms} / 8^{\circ} \text { (minTe, } \\
\text { minTR) }\end{array}$ \\
\hline $\begin{array}{l}\text { 3D T2-weighted } \\
\text { FLAIR }\end{array}$ & WML volume & $\begin{array}{l}\text { Predictor of primary } \\
\text { outcome }\end{array}$ & $\begin{array}{l}3 \mathrm{D}, 24 \mathrm{~cm}, 1 \mathrm{~mm} / 0 \mathrm{~mm}, 38,256 \times \\
256\end{array}$ & $140 \mathrm{~ms} / 9000 \mathrm{~ms} / 90^{\circ}$ \\
\hline Axial 3D QSM & $\begin{array}{l}\text { Neurodegeneration Brain iron } \\
\text { content }\end{array}$ & $\begin{array}{l}\text { Predictor of primary } \\
\text { outcome }\end{array}$ & $3 \mathrm{D}, 24 \mathrm{~cm}, 2 \mathrm{~mm} / 0 \mathrm{~mm}, 192 \times 192$ & $29.5 \mathrm{~ms} / 3 \mathrm{~ms} / 8^{\circ}$ \\
\hline 3D Proton Density & WML volume & & 3D SPGR, $1 \mathrm{~mm} / 0 \mathrm{~mm}, 256 \times 256$ & \\
\hline Diffusion tensor DWI & $\begin{array}{l}\text { Microstructure Acute cytotoxic } \\
\text { ischemia }\end{array}$ & & $\begin{array}{l}2 \mathrm{D}, 24 \mathrm{~cm}, 3.5 \mathrm{~mm} / 0 \mathrm{~mm}, 38 \\
144 \times 144 \text { matrix }\end{array}$ & $\begin{array}{l}70 \mathrm{~ms}-80 \mathrm{~ms} / \\
13,000 \mathrm{~ms} / 90^{\circ}\end{array}$ \\
\hline Axial T2 star & Microhemorrhage & & $\begin{array}{l}2 \mathrm{D}, 24 \mathrm{~cm}, 3.5 \mathrm{~mm} / 0 \mathrm{~mm}, 38 \\
256 \times 224\end{array}$ & $140 \mathrm{~ms} / 9000 \mathrm{~ms} / 90^{\circ} 7$ \\
\hline
\end{tabular}


Table 3 PREVENT Neuropsychological Battery

\begin{tabular}{|c|c|c|}
\hline Domain & Test & Description \\
\hline Attention & Trail Making A [52] & $\begin{array}{l}\text { Measure of attention, speed and mental flexibility through connecting numbers } \\
\text { from } 1 \text { to } 25 \text { in ascending order. }\end{array}$ \\
\hline $\begin{array}{l}\text { Processing } \\
\text { Speed }\end{array}$ & Digit Symbol Coding Test (WAIS-IV) [53] & $\begin{array}{l}\text { Assessment consisting of } 9 \text { digit-symbol pairs followed by a list of digits. Subject } \\
\text { instructed to fill in the corresponding symbol within } 120 \mathrm{~s} \text {. }\end{array}$ \\
\hline Verbal Memory & $\begin{array}{l}\text { WHO/UCLA's Auditory Verbal Learning } \\
\text { Test [54] }\end{array}$ & $\begin{array}{l}\text { Measure of verbal learning and memory. Subject asked to repeat a list of words (List A) } \\
\text { for } 5 \text { consecutive trials. An interference trial is introduced (List B) followed by immediate } \\
\text { recall and a } 25 \text {-min delayed recall. }\end{array}$ \\
\hline Visual Memory & $\begin{array}{l}\text { Brief Visuospatial Memory Test - } \\
\text { Revised (BVMT) [55] }\end{array}$ & $\begin{array}{l}\text { Measure of visual learning and memory. Target figures presented to subject for } 10 \mathrm{~s} \text { for } 3 \\
\text { consecutive drawing trials. After a } 25 \text {-min delay subject is asked to redraw target figures. } \\
\text { Recognition trial is almost administered using } 6 \text { novel and } 6 \text { target figures. }\end{array}$ \\
\hline \multirow[t]{3}{*}{$\begin{array}{l}\text { Executive } \\
\text { Function }\end{array}$} & Stroop Color Word Test [56] & $\begin{array}{l}\text { Measure of executive function to assess cognitive control. Subjects instructed to read } \\
\text { colors out loud while ignoring the printed words in } 45-5 \text {. }\end{array}$ \\
\hline & Trail Making B [52] & $\begin{array}{l}\text { Measure of mental flexibility. Subject asked to connect alternating numbers (1-13) and } \\
\text { letters (A-L). }\end{array}$ \\
\hline & Clox-1: Executive Clock Drawing [57] & $\begin{array}{l}\text { Measure of visual spatial construction and executive abilities; also screens for dementia. } \\
\text { The subject is instructed to draw a clock with hands and numbers and a specific time. }\end{array}$ \\
\hline \multirow[t]{2}{*}{$\begin{array}{l}\text { Working } \\
\text { Memory }\end{array}$} & Digit Span Forward [58] & $\begin{array}{l}\text { Test of working memory. Subject is asked to repeat back a list of numbers verbatim as } \\
\text { they increase in difficulty. }\end{array}$ \\
\hline & Digit Span Backwards [58] & $\begin{array}{l}\text { Test of working memory. Subject is asked to repeat the list of words in backwards order } \\
\text { as they increase in difficulty. }\end{array}$ \\
\hline \multirow[t]{2}{*}{ Language } & Boston Naming Test (Short form) [59] & $\begin{array}{l}\text { Assessment of visual naming ability. Subject is asked to name } 15 \text { objects after being } \\
\text { presented with an illustration. }\end{array}$ \\
\hline & Complex Ideation Material [60] & $\begin{array}{l}\text { Assessment of error detection that may be attributed to dementia. Subject is asked yes/no } \\
\text { questions about areas that are considered general knowledge. Subject is then read two } \\
\text { stories and asked yes/no questions post-comprehension. }\end{array}$ \\
\hline $\begin{array}{l}\text { Premorbid } \\
\text { Intelligence }\end{array}$ & $\begin{array}{l}\text { North American Adult Reading Test } \\
\text { (NAART) [61] }\end{array}$ & $\begin{array}{l}\text { Measure of premorbid intelligence. The subject is asked to read a list of } 61 \text { words out } \\
\text { loud. }\end{array}$ \\
\hline Mood & $\begin{array}{l}\text { Center for Epidemiological Studies - } \\
\text { Depression Scale (CES-D) [62] }\end{array}$ & $\begin{array}{l}\text { Self-reported questionnaire. The subject is asked to fill out a questionnaire that pertains to } \\
\text { their mood and well-being. }\end{array}$ \\
\hline \multirow[t]{2}{*}{$\begin{array}{l}\text { Cognitive } \\
\text { Screening Tests }\end{array}$} & $\begin{array}{l}\text { Montreal Cognitive Assessment } \\
\text { (MoCA) [63] }\end{array}$ & $\begin{array}{l}\text { Assessment of multiple cognitive domains; sensitive to mild cognitive impairment and } \\
\text { dementia. }\end{array}$ \\
\hline & $\begin{array}{l}\text { Addenbrooke's Cognitive Assessment - } \\
\text { Revised (ACE-R) [64] }\end{array}$ & $\begin{array}{l}\text { Assessment of multiple cognitive domains; sensitive to } \mathrm{MCl} \text { and dementia. The test has a } \\
\text { built in mini mental state examination (MMSE). }\end{array}$ \\
\hline
\end{tabular}

\section{Power analyses}

The PREVENT study will recruit 220 TIA patients to participate in this study and compare them to 220 controls, which is inclusive of $20 \%$ attrition rate in the whole sample, informed by our preliminary data and by other well documented longitudinal studies [22-24]. The study is powered based on multiple linear regressions of the association between the primary outcome of interest, first year cerebral atrophy rate (R1), and group effect, after adjusting for other socio-demographic, clinical, and vascular risk factors, and other potential confounders. With a sample size of 440 , the study will have at least $85 \%$ power to detect a $30 \%$ group effect size (i.e. TIA versus control) following baseline measurement and follow up measurement taken at Y1, informed by similar rates of whole brain atrophy in published reports of prodromal dementia [25, 26], and our pilot data [27, 28]. This sample size will provide at least $90 \%$ power to detect a standardized difference of 0.35 between TIA and control groups for change over time on the WHO/
UCLA AVLT (verbal memory) and Trails A and B tests (processing speed/executive function).

\section{Statistical analyses}

Statistical analysis will include descriptive statistics to compare the mean, median, standard deviations, and frequency distribution $\mathrm{s}$ of all variables.

A mixed repeated measure regression model will be used to model the association between overall cognitive domain specific and composite $\mathrm{z}$-score variable measures at baseline, 1 year, and 3 years and patient group (TIA versus healthy control), after adjusting for demographic characteristics, baseline cognitive function, vascular risk factors mentioned before, in vivo biomarkers, and patient interactions as fixed effects covariates. The size of the standardized regression coefficients associated with each predictor will be used to quantify its relative importance in predicting rate of cognitive decline in patients versus controls. A random intercept will be included to account for subject-specific variation in 
cognitive scores. The 95\% confidence intervals and the corresponding $p$-values for adjusted group effect on overall cognitive outcomes will be estimated.

Finally, we will develop novel prediction models based on machine learning and generalized estimating equation models to identify individual TIA patients with a high likelihood to develop cognitive decline. The basic idea of this is to predict occurrence of cognitive decline using prediction models developed and trained on the longitudinal data with known clinical outcome (cognitive decline yes / no), which can then be used to predict cognitive impairment in new patients based on the same features used for training of the high-level machine learning model. More precisely, we will develop prediction models based on random forest [29], support vector machines [30], deep neural networks [31], and quadratic inference function classifiers for predicting the occurrence of dementia using available baseline information such as cognitive test results, blood and CSF parameters, as well as quantitative image-based biomarkers such as regional QSM values, volumetric brain and hippocampal values, and white matter lesion (WML) load. The evaluation of the prediction models based on the TIA and control cohorts will be conducted using well-established cross validation techniques. This means that we will, for example, exclude one patient with known dementia outcome from the training set. After this, the prediction model trained based on the remaining patients can be used to predict dementia outcome for the one patient not part of the training set and the predicted outcome can be compared to the real outcome. By iteratively repeating this so-called leave-one-out cross validation for all patients available, the accuracy of the prediction model can be determined and used to identify the optimal high-level machine learning method for this purpose.

\section{Discussion}

In light of social and economic burdens, early identification of high-risk patients for dementia is the most important step in prevention and postponement $[32,33]$. With no cure and recent clinical trial failures, it is becoming increasingly important that trials must be redesigned with a focus on high-risk populations and standardized biomarkers, which include clinical, demographic, imaging and neuropsychological considerations. The PREVENT study proposes the early identification of people at risk for late-life cognitive decline as the single most important approach for trial designs. To date, studies have established a link between vascular risk and stroke, and late life cognitive impairment but overlooked fundamental challenges such as the efficacy of vascular reduction treatment (antihypertensive treatments [34-38], diabetes management, and cholesterol lowering therapy [39]) on slowing cognitive decline, thus leading to inconclusive results. Special consideration needs to be given to identifying patients at the highest risk of dementia (i.e. TIA patients) since these patients are most likely to benefit from earlier intervention [40] before symptoms manifest, and from therapies that focus on vascular risk reduction [34]. Intervention trials such as the Finnish Geriatric Interventions to Prevent Cognitive Impairment (FINGER) study and the Prevention of Dementia by Intensive Vascular care (preDIVA) trial, show that focusing on diet, exercise, cognitive training, and vascular risk management as a multi-domain treatment approach improves or maintains cognitive function in at risk elderly when compared to healthy controls $[24,41]$. The potential mechanisms of disease progression ( $\mathrm{AD}$, vascular disease or both), response of these multi-domain therapeutic interventions, and their long-term benefits remain unknown [42]. However, epidemiological studies show that the incidence or age specific prevalence of dementia has declined in the past 20 years [43-45], implying that the risk of dementia is modifiable through vascular risk reduction therapies. The early identification of patients at greatest risk of cognitive decline, by measuring change in cognition, is an important issue to be addressed by the PREVENT study.

The PREVENT study is expected to support the concept that rate of cerebral atrophy is a meaningful measure of disease progression that precedes cognitive decline and provide justification for the use of rates of cerebral atrophy as an outcome in pre-clinical dementia prevention trials. The PREVENT study in its design will stratify dementia risk according to biological markers of neurodegeneration, and small vessel cerebrovascular disease. We anticipate that the PREVENT study will demonstrate the temporal order of biomarker (in vivo $\mathrm{AD}$ and small vessel disease features) change as shown in the figure below with more advanced decline of brain volume occurring in order as follows: Alzheimer's pathology plus cerebrovascular disease, Alzheimer's disease in isolation, small vessel cerebrovascular disease and low vascular risk group without identifiable in vivo markers of either vascular disease or AD, all starting before clinical symptoms manifest (Fig. 1).

We anticipate that recruitment will be the most important challenge to the feasibility of the PREVENT Study. Clinical evaluations, cognitive tests, and the MRI protocol have been designed to minimize patient fatigue, and will be only performed yearly (inclusive of year 5). Recruitment is ahead of schedule providing powerful evidence that enrollment of TIA patients and healthy controls will be complete by the end of 2018. We are actively recruiting from a repository of healthy community volunteers (Calgary Normative Study). We anticipate that by the end of 2019 we will have completed our 


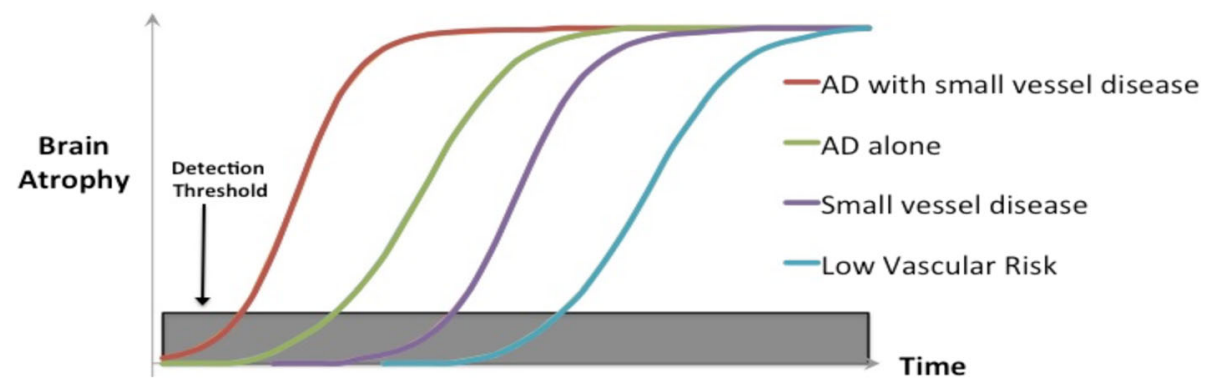

Fig. 1 PREVENT stratification of dementia risk by biomarker profile for future dementia prevention clinical trials

primary outcome measure of early rates of brain atrophy (R1). By 2021, secondary outcome measures of rates of brain atrophy will have been completed 3 years (R2) and biomarkers of Alzheimer's disease in WML will have been analyzed. All patients will have completed 4 years of serial neuropsychological assessments.

Our sample size calculations for the PREVENT study are inclusive of an estimated attrition rate of $20 \%$, which is similar to drop out rates in other longitudinal studies of cerebrovascular disease and cognition [46]. Potential bias of our results through the withdrawal or death of subjects at highest risk of dementia will be mitigated by the age inclusion criteria (45-75). Moreover, unlike stroke patients, TIA patients will be able to physically and cognitively comply with serial cognitive and MR imaging. All study participants will be under regular surveillance during clinical reassessments for the development of cardiovascular events and death. Confirmed cases of recurrent stroke will be excluded from our primary outcome analysis; recurrence is anticipated to be low $(<2 \%)$ [47].

A proportion of PREVENT subjects may have diffusion-weighted lesions (possibly up to 30\%) [14], but previous studies have shown that presence of such small silent infarcts may not explain the cognitive profile [48], nor the progressive cognitive decline [49], perhaps implicating neurodegenerative and inflammatory processes $[50,51]$. The presence of DWI lesions may be another predictor of progressive brain atrophy. Exploring disease mechanisms implicated in the recently reported interactions between incident stroke and persistent progressive cognitive decline will be important to furthering our understanding of the disease interaction of neurodegenerative and cerebrovascular processes on cognitive decline [49].

We have set rigorous standards for maintaining the highest quality MR images, including the application of similar benchmark standards used by the Alzheimer's Disease Neuroimaging group (adni.loni.usc.edu). Objective quality assurance to detect image distortion will be diligently followed to measure properties that include grading calibration, image contrast, and signal to noise ratio. Any scans that fail quality control will be repeated within 4 weeks.

The PREVENT study will be the first critical step for identifying individuals at increased risk of late life cognitive decline. Future steps will target individuals at the highest risk of dementia before symptoms develop, thereby identifying an enriched disease group to test preventative and disease modifying strategies in clinical trials that aim to reduce the microscopic brain tissue loss over a relatively short period of time, thereby optimizing the opportunity for preventing dementia in the future.

\section{Abbreviations}

AD: Alzheimer's disease; APOE: Apolipoprotein E; BP: Blood pressure; CSF: Cerebrospinal fluid; DWI: Diffusion weighted imaging; FINGER: Finnish Geriatric Interventions to Prevent Cognitive Impairment and Disability study; MRI: Magnetic resonance imaging; MS: Multiple sclerosis:

PREVENT: Predementia Neuroimaging of Transient Ischemic Attack study; QSM: Quantitative susceptibility mapping; TIA: Transient ischemic attack; VaD: Vascular Dementia; VCl: Vascular cognitive impairment; WHO/UCLA AVLT: World Health Organization/University of California Los Angeles auditory verbal learning test; WML: White matter lesion

\section{Acknowledgements}

We thank the participants and the research staff at the Calgary Stroke Program, Calgary Image Processing and Analysis Centre, Calgary Normative Study and Seaman Family MR Research Center for their cooperation and support.

\section{Funding}

The present study is supported by Heart and Stroke Foundation of Canada, operating grant (G-16-00012595). The Calgary Normative data used as part of the normal controls portion of this study was funded by the Canadian Institutes for Health Research (220064). We thank Linda Andersen, Cheryl McCreary, and Marina Salluzzi for enabling access to these data.

Availability of data and materials

The datasets generated and/or analyzed during the current study are available from the corresponding author on reasonable request.

\section{Authors' contributions}

$\pi T S, E E S, R S L, R F, S B C, N D F, P A B$ have made substantial contributions to conception and design of this study. ST and PAB wrote the draft of the manuscript and all authors were involved in revising the manuscript critically for important intellectual content. ST was involved in coordinating the study, recruitment, and administering neuropsychological tests. TTS provided significant statistical guidance for the project. RSL conceptualized the neuropsychological test battery and oversaw research assistant (RA) training for administration. RF and NDF provided guidance related to imaging modalities and the conceptual framework for analysis. All authors have given full approval of the version to be published. 


\section{Ethics approval and consent to participate}

The study has been approved by the Conjoint Health and Research Ethics Board (CHREB; 13-0240). Written informed consent was obtained from all participants.

\section{Consent for publication}

Not applicable.

\section{Competing interests}

The authors declare that they have no competing interests.

\section{Publisher's Note}

Springer Nature remains neutral with regard to jurisdictional claims in published maps and institutional affiliations.

\begin{abstract}
Author details
${ }^{1}$ Calgary Stroke Program, Department of Clinical Neurosciences, Foothills Medical Centre, 1403 - 29 Street NW, Calgary, AB, Canada. ${ }^{2}$ Seaman Family MR Center, Foothills Medical Centre, 1403 29th Street NW, Calgary, AB, Canada. ${ }^{3}$ Department of Community Health Sciences \& O'Brien Institute for Public Health, University of Calgary, 3280 Hospital Drive NW, Calgary, AB, Canada. ${ }^{4}$ Hotchkiss Brain Institute, Foothills Medical Center, Room 1A10 Health Research Innovation Center, 3330 Hospital Drive NW, Calgary, AB T2N 4N1, Canada. ${ }^{5}$ Department of Radiology and Clinical Neurosciences, Cumming School of Medicine, University of Calgary, Calgary, AB, Canada.
\end{abstract}

Received: 6 July 2017 Accepted: 9 July 2018

Published online: 16 July 2018

\section{References}

1. Norton S, Matthews FE, Barnes DE, Yaffe K, Brayne C. Potential for primary prevention of Alzheimer's disease: an analysis of population-based data. Lancet. Neurol. [Internet]. 2014;13:788-94. Available from: http://www.ncbi. nlm.nih.gov/pubmed/25030513

2. Easton JD, Saver UL, Albers GW, Alberts MJ, Chaturvedi S, Feldmann E, et al. Definition and evaluation of transient ischemic attack: a scientific statement for healthcare professionals from the American Heart Association/American Stroke Association Stroke Council; Council on Cardiovascular Surgery and Anesthesia; Council on Cardio. Stroke. [Internet]. 2009:40:2276-2293. Available from: papers3://publication/doi/https://doi.org/10.1161/ STROKEAHA.108.192218

3. Li L, Yiin GS, Geraghty OC, Schulz UG, Kuker W, Mehta Z, et al. Incidence, outcome, risk factors, and long-term prognosis of cryptogenic transient ischaemic attack and ischaemic stroke: A population-based study. Lancet Neurol. [Internet]. Li et al. Open Access article distributed under the terms of CC BY-NC-ND; 2015;14:903-13. Available from: https://doi.org/10.1016/ S1474-4422(15)00132-5.

4. Pendlebury S, Chen P-J, Mehta Z, Rothwell PM, Study O. Long-term risk of dementia after TIA and stroke: current estimates from a large populationbased study. Cerebrovasc. Dis. [Internet]. 2013;35:187. Available from: https:// www.rdm.ox.ac.uk/publications/448620

5. Li J-Q, Tan L, Wang H-F, Tan M-S, Tan L, Xu W, et al. Risk factors for predicting progression from mild cognitive impairment to Alzheimer's disease: a systematic review and meta-analysis of cohort studies. J. Neurol. Neurosurg. Psychiatry [Internet]. 2016:1-9. Available from: http://jnnp.bmj. com/cgi/doi/10.1136/jnnp-2014-310095

6. Heath CA, Mercer SW, Guthrie B. Vascular comorbidities in younger people with dementia: a cross-sectional population-based study of 616245 middleaged people in Scotland. J Neurol Neurosurg Psychiatry [Internet]. 2014; jnnp-2014-309033-. Available from: http://jnnp.bmj.com/content/early/2014/ 11/18/jnnp-2014-309033

7. GM MK, Knopman DS, Chertkow H, Hyman BT, Jack CR, Kawas CH, et al. The diagnosis of dementia due to Alzheimer's disease: recommendations from the National Institute on Aging-Alzheimer's Association workgroups on diagnostic guidelines for Alzheimer's disease. Alzheimers. Dement. [Internet]. 2011;7:263-9. Available from: http://www.ncbi.nlm.nih.gov/pubmed/ 21514250

8. Liu Y, Yu J-T, Wang H-F, Han P-R, Tan C-C, Wang C, et al. APOE genotype and neuroimaging markers of Alzheimer's disease: systematic review and meta-analysis. J Neurol Neurosurg Psychiatry [Internet]. 2015:86:127-134. Available from: http:/www.ncbinlm.nih.gov/pubmed/24838911
9. Johns MW. Daytime sleepiness, snoring, and obstructive sleep apnea. The Epworth Sleepiness Scale. Chest [Internet]. 1993;103:30-6. Available from: http://www.ncbi.nlm.nih.gov/pubmed/8417909

10. Webb AJS, Rothwell PM. Physiological correlates of beat-to-beat, ambulatory, and day-to-day home blood pressure variability after transient ischemic attack or minor stroke. Stroke [Internet]. 2014;45:533-8. Available from: https://www.ncbi.nlm.nih.gov/pubmed/24407950.

11. Coutts SB, Wein TH, Lindsay MP, Buck B, Cote R, Ellis P, et al. Canadian Stroke Best Practice Recommendations: secondary prevention of stroke guidelines, update 2014. Int. J. Stroke [Internet]. 2015;10:282-91. Available from: http://www.ncbi.nlm.nih.gov/pubmed/25535808

12. Lista S, Garaci FG, Ewers M, Teipel S, Zetterberg H, Blennow K, et al. CSF A 1 1-42 combined with neuroimaging biomarkers in the early detection, diagnosis and prediction of Alzheimer's disease. Alzheimers. Dement. [Internet]. Elsevier Ltd; 2014;10:381-392. Available from: http://www.ncbi. nlm.nih.gov/pubmed/23850330

13. Mattsson N, Insel P, Nosheny R, Zetterberg H, Trojanowski JQ, Shaw LM, et al. CSF protein biomarkers predicting longitudinal reduction of CSF $\beta$ amyloid42 in cognitively healthy elders. Transl. Psychiatry [Internet]. 2013;3: e293. Available from: http://www.ncbi.nlm.nih.gov/pubmed/23962923

14. Brazzelli M, Chappell FM, Miranda H, Shuler K, Dennis M, PAG S, et al. Diffusion-weighted imaging and diagnosis of transient ischemic attack. Ann. Neurol. [Internet]. 2014;75:67-76. Available from: http://www.ncbi.nlm.nih. gov/pubmed/24085376

15. Smith SM, Zhang $Y$, Jenkinson $M$, Chen J, Matthews PM, Federico A, et al. Accurate, robust, and automated longitudinal and cross-sectional brain change analysis. Neuroimage [Internet]. 2002;17:479-89. Available from: http://www.ncbi.nlm.nih.gov/pubmed/12482100

16. Nugent AC, Luckenbaugh DA, Wood SE, Bogers W, Zarate CA, Drevets WC Automated subcortical segmentation using FIRST: test-retest reliability, interscanner reliability, and comparison to manual segmentation. Hum Brain Mapp [Internet]. 2013;34:2313-2329. Available from: http://www.ncbi.nlm. nih.gov/pubmed/22815187

17. Thomann PA, Wüstenberg T, Nolte HM, Menzel PB, Wolf RC, Essig M, et al. Hippocampal and entorhinal cortex volume decline in cognitively intact elderly. Psychiatry Res. [Internet]. 2013;211:31-6. Available from: http://www. ncbi.nlm.nih.gov/pubmed/23168382

18. Smith SM, Jenkinson M, Woolrich MW, Beckmann CF, TEJ B, Johansen-Berg $\mathrm{H}$, et al. Advances in functional and structural MR image analysis and implementation as FSL. Neuroimage [Internet]. 2004;23(Suppl 1):S208-19. Available from: http://www.ncbi.nlm.nih.gov/pubmed/15501092

19. Jenkinson M, Beckmann CF, Behrens TEJ, Woolrich MW, Smith SM. FSL. Neuroimage [Internet]. 2012;62:782-790. Available from: http://www.ncbi. nlm.nih.gov/pubmed/21979382

20. Lauzon ML, McCreary CR, McLean DA, Salluzzi M, Frayne R. Quantitative susceptibility mapping at 3 T: comparison of acquisition methodologies. NMR Biomed [nternet]. 2017;30. Available from: http//umw.ncbi.nlm.nih.gov/pubmed/26887659

21. Hachinski V, ladecola C, Petersen RC, Breteler MM, Nyenhuis DL, Black SE, et al. National Institute of Neurological Disorders and Stroke-Canadian stroke network vascular cognitive impairment harmonization standards. Stroke [Internet]. 2006;37:2220-2241. Available from: http://www.ncbi.nlm.nih.gov/ pubmed/16917086

22. Gouw AA, van der Flier WM, Fazekas F, van Straaten ECW, Pantoni L, Poggesi A, et al. Progression of white matter hyperintensities and incidence of new lacunes over a 3-year period: the Leukoaraiosis and disability study. Stroke [Internet]. 2008, 39:1414-1420. Available from: http:/www.ncbinlm.nih.gov/pubmed/18323505

23. Madureira S, Verdelho A, Ferro J, Basile A-M, Chabriat H, Erkinjuntti T, et al. Development of a neuropsychological battery for the Leukoaraiosis and disability in the elderly study (LADIS): experience and baseline data. Neuroepidemiology [Internet]. 2006;27:101-116. Available from: http://www. ncbi.nlm.nih.gov/pubmed/16943684

24. Ngandu T, Lehtisalo J, Solomon A, Levälahti E, Ahtiluoto S, Antikainen R, et al. A 2 year multidomain intervention of diet, exercise, cognitive training, and vascular risk monitoring versus control to prevent cognitive decline in at-risk elderly people (FINGER): a randomised controlled trial. Lancet (London, England) [Internet]. 2015;385:2255-63. Available from: http://www. ncbi.nlm.nih.gov/pubmed/25771249

25. Evans MC, Barnes J, Nielsen C, Kim LG, Clegg SL, Blair M, et al. Volume changes in Alzheimer's disease and mild cognitive impairment: cognitive associations. Eur Radiol [Internet]. 2010;20:674-682. Available from: http://www.ncbinlm.nih.gov/ pubmed/19760240 
26. Ahmed RM, Paterson RW, Warren JD, Zetterberg H, O'Brien JT, Fox NC, et al. Biomarkers in dementia: clinical utility and new directions. Neurol Neurosurg Psychiatry. 2014;85:1426-34. Available from: https:// www.ncbi.nlm.nih.gov/pubmed/25261571

27. Munir MA, Zamboni G, Griffanti L, Zhang Y, Tariq S, Smith EE, et al. TIA and Minor Stroke Patients Experience Higher Brain Atrophy During Preclinical Stages. Tokyo. 2015; Available from: http://www2.convention.co.jp/vas-cogworld2015/program/Program_Poster.pdf.

28. Munir MA, Zamboni G, Griffanti L, Zhang Y, Tariq S, Smith EE, et al. Cognitive decline at 3 years in minor stroke and TIA patients. Tokyo. 2015; Available from: http://www2.convention.co.jp/vas-cog-world2015/program/ Program_Poster.pdf

29. Lebedev A V, Westman E, Van Westen GJP, Kramberger MG, Lundervold A, Aarsland D, et al. Random Forest ensembles for detection and prediction of Alzheimer's disease with a good between-cohort robustness. Neurolmage. Clin. [Internet]. 2014;6:115-125. Available from: https://www.ncbi.nlm.nih. gov/pubmed/25379423.

30. Ferreira LK, Rondina JM, Kubo R, Ono CR, Leite CC, Smid J, et al. Support vector machine-based classification of neuroimages in Alzheimer's disease: direct comparison of FDG-PET, rCBF-SPECT and MRI data acquired from the same individuals. Rev Bras Psiquiatr [Internet]. 2017; Available from: http:// www.scielo.br/scielo.php?script=sci_arttext\&pid=\$151644462017005017101\&lng=en\&tlng=en.

31. Hosseini-Asl E, Gimel'farb G, El-Baz A. Alzheimer's disease diagnostics by a deeply supervised adaptable 3D convolutional network. 2016; Available from: http://arxiv.org/abs/1607.00556

32. Prince M, Albanese E, Guerchet M, Prina M. World Alzheimer report 2014 dementia and risk reduction: an analysis of protective and modifiable factors. London Alzheimer's Dis. Int. [Internet]. 2014:104. Available from: https://www.alz.co.uk/research/WorldAlzheimerReport2014.pdf

33. Haan MN, Wallace R. Can dementia be prevented? Brain aging in a population-based context. Annu Rev Public Health [Internet]. 2004;25:1-24. Available from: http://www.ncbi.nlm.nih.gov/pubmed/15015910

34. Prevention of stroke by antihypertensive drug treatment in older persons with isolated systolic hypertension. Final results of the Systolic Hypertension in the Elderly Program (SHEP). SHEP Cooperative Research Group. JAMA [Internet]. 1991;265:3255-3264. Available from: http://www.ncbi.nlm.nih.gov/ pubmed/2046107

35. Staessen JA, Fagard R, Thijs L, Celis H, Arabidze GG, Birkenhäger WH, et al. Randomised double-blind comparison of placebo and active treatment for older patients with isolated systolic hypertension. The Systolic Hypertension in Europe (Syst-Eur) Trial Investigators Lancet (London, England) [Internet]. 1997;350:757-64. Available from: http://www.ncbi.nlm.nih.gov/pubmed/ 9297994

36. Tzourio C, Anderson C, Chapman N, Woodward M, Neal B, MacMahon $S$, et al. Effects of blood pressure lowering with perindopril and indapamide therapy on dementia and cognitive decline in patients with cerebrovascular disease. Arch. Intern. Med. [Internet]. 2003;163: 1069-75. Available from: http://www.ncbi.nlm.nih.gov/pubmed/ 12742805

37. Lithell H, Hansson L, Skoog I, Elmfeldt D, Hofman A, Olofsson B, et al. The study on cognition and prognosis in the elderly (SCOPE): principal results of a randomized double-blind intervention trial. J Hypertens [Internet]. 2003;21: 875-886. Available from: http://www.ncbi.nlm.nih.gov/pubmed/12714861

38. Peters R, Beckett N, Forette F, Tuomilehto J, Clarke R, Ritchie C, et al. Incident dementia and blood pressure lowering in the Hypertension in the Very Elderly Trial cognitive function assessment (HYVET-COG): a doubleblind, placebo controlled trial. Lancet. Neurol. [Internet]. 2008;7:683-9. Available from: http://www.ncbi.nlm.nih.gov/pubmed/18614402

39. Mielke MM, Zandi PP, Sjögren M, Gustafson D, Ostling S, Steen B, et al. High total cholesterol levels in late life associated with a reduced risk of dementia. Neurology [Internet]. 2005;64:1689-1695. Available from: http:// www.ncbi.n/m.nih.gov/pubmed/15911792

40. Schneider LS. Reduce vascular risk to prevent dementia? Lancet [Internet] 2016;388:738-40. Available from: http://linkinghub.elsevier.com/retrieve/pii/ S0140673616311291

41. van Charante EPM, Richard E, Eurelings LS, van Dalen J-W, Ligthart SA, van Bussel EF, et al. Effectiveness of a 6-year multidomain vascular care intervention to prevent dementia (preDIVA): a cluster-randomised controlled trial. Lancet [Internet]. Elsevier Ltd; 2016;388:797-805. Available from: https://doi.org/10.1016/S0140-6736(16)30950-3.
42. Tariq S, Barber PA. Dementia risk and prevention by targeting modifiable vascular risk factors. J. Neurochem. [Internet]. 2017 [cited 2017 Sep 9]; Available from: http://doi.wiley.com/10.1111/jnc.14132

43. Prince M, Ali G-C, Guerchet M, Prina AM, Albanese E, Wu Y-T, et al. Recent global trends in the prevalence and incidence of dementia, and survival with dementia. Alzheimers. Res. Ther. [Internet]. Alzheimer's Research \& Therapy. 2016;8:23. Available from: http://alzres.biomedcentral.com/articles/ 10.1186/s13195-016-0188-8

44. Qiu C, Kivipelto M, von Strauss E. Epidemiology of Alzheimer's disease: occurrence, determinants, and strategies toward intervention. Dialogues Clin. Neurosci. [internet], Available from. 2009;11:111-28. http://www.ncbi. nlm.nih.gov/pubmed/19585947

45. Langa KM. Is the risk of Alzheimer's disease and dementia declining? Alzheimer's Res. \{\&\} Ther. [Internet]. 2015;7:34. Available from: https://doi. org/10.1186/s13195-015-0118-1\%5Cnhttp://alzres.com/content/7/1/ 34\%5Cnhttp://www.pubmedcentral.nih.gov/articlerender.fcgi?artid= 4374373\&tool=pmcentrez\&rendertype $=$ abstract

46. Mandzia JL, Smith EE, Horton M, Hanly P, Barber PA, Godzwon C, et al. Imaging and baseline predictors of cognitive performance in minor ischemic stroke and patients with transient ischemic attack at 90 days Stroke. 2016;47:726-31. Available from: http://stroke.ahajournals.org/lookup/ doi/10.1161/STROKEAHA.115.011507

47. Coutts SB, Simon JE, Eliasziw M, Sohn C-H, Hill MD, Barber PA, et al. Triaging transient ischemic attack and minor stroke patients using acute magnetic resonance imaging. Ann Neurol [Internet]. 2005;57:848-854. Available from: http://www.ncbi.nlm.nih.gov/pubmed/15929051

48. van Rooij FG, Schaapsmeerders P, Maaijwee NAM, van Duijnhoven DAHJ, de Leeuw F-E, Kessels RPC, et al. Persistent cognitive impairment after transient ischemic attack. Stroke [Internet]. 2014;45:2270-2274. Available from: http:// www.ncbi.nlm.nih.gov/pubmed/25070959

49. Levine DA, Galecki AT, Langa KM, Unverzagt FW, Kabeto MU, Giordani B, et al. Trajectory of cognitive decline after incident stroke. JAMA [Internet]. 2015;314:41-51. Available from: http://www.ncbi.nlm.nih.gov/pubmed/ 26151265

50. Whitehead SN, Cheng G, Hachinski VC, Cechetto DF. Progressive increase in infarct size, neuroinflammation, and cognitive deficits in the presence of high levels of amyloid. Stroke [Internet]. 2007;38:3245-3250. Available from: http://www.ncbi.nlm.nih.gov/pubmed/17962591

51. Amtul Z, Nikolova S, Gao L, Keeley RJ, Bechberger JF, Fisher AL, et al. Comorbid $A \beta$ toxicity and stroke: hippocampal atrophy, pathology, and cognitive deficit. Neurobiol. Aging [Internet]. 2014;35:1605-14. Available from: http://www.ncbi.nlm.nih.gov/pubmed/24491422

52. Arnett JA, Labovitz SS. Effect of physical layout in performance of the trail making test. Psychol Assess [Internet] 1995;7:220-221. Available from: http:// doi.apa.org/getdoi.cfm?doi=10.1037/1040-3590.7.2.220

53. Strauss E. A compendium of neuropsychological tests: Administration, norms, and commentary. Third. Sherman EMS, Spreen O, editors. Oxford University Press; 2006.

54. Maj M, D'Elia L, Satz P, Janssen R, Zaudig M, Uchiyama $C$, et al. Evaluation of two new neuropsychological tests designed to minimize cultural bias in the assessment of HIV-1 seropositive persons: a WHO study. Arch. Clin. Neuropsychol. [Internet]. 1993;8:123-35. Available from: http://www.ncbi. nlm.nih.gov/pubmed/14589670

55. Benedict RHB. Brief visuospatial memory test-revised. PAR; 2012.

56. Stroop JR. Studies of interference in serial verbal reactions. J Exp Psychol [Internet]. 1935;18:643-62. Available from: http://content.apa.org/journals/ xge/18/6/643

57. Royall D, Cordes J, Polk M. CLOX: an executive clock drawing task. J Neurol Neurosurg Psychiatry [Internet]. 1998;64:588-94. Available from: http://www. ncbi.nlm.nih.gov/pmc/articles/PMC2170069/pdf/v064p00588.pdf

58. Kaufman AS, Lichtenberger EO. Assessing adolescent and adult intelligence. 3rd ed. In: Wiley; 2006.

59. Lansing $A E$, Ivnik RJ, Cullum CM, Randolph C. An empirically derived short form of the Boston naming test. Arch. Clin. Neuropsychol. [Internet]. 1999;14:481-7. Available from: http://www.ncbi.nlm.nih.gov/ pubmed/14590575

60. Erdodi LA, Tyson BT, Abeare CA, Lichtenstein JD, Pelletier CL, Rai JK, et al. The BDAE complex ideational material???A measure of receptive language or performance validity? Psychol. Inj. Law [Internet]. Psychological Injury and Law; 2016:9:112-120. Available from: https://doi.org/10.1007/s12207-0169254-6 
61. Blair JR, Spreen O. Predicting premorbid IQ: a revision of the national adult reading test. Clin Neuropsychol [Internet] 1989;3:129-136. Available from: http://www.tandfonline.com/doi/abs/10.1080/13854048908403285

62. Radloff $L S$. The CES-D scale: A self report depression scale for research in the general population. Appl Psychol Meas. 1977;1:385-401.

63. Nasreddine Z, Phillips N, Bédirian V, Charbonneau S, Whitehead V, Colllin I, et al. The Montreal cognitive assessment, MoCA: a brief screening tool for mild cognitive impairment. J Am Geriatr Soc [lnternet]. 2005;53:695-9. Available from: http://onlinelibrary.wiley.com/doi/10.1111/j.1532-5415.2005. 53221.x/full

64. Larner AJ. Dementia in clinical practice: a neurological perspective: studies in the dementia clinic: Springer; 2012.

Ready to submit your research? Choose BMC and benefit from:

- fast, convenient online submission

- thorough peer review by experienced researchers in your field

- rapid publication on acceptance

- support for research data, including large and complex data types

- gold Open Access which fosters wider collaboration and increased citations

- maximum visibility for your research: over $100 \mathrm{M}$ website views per year

At BMC, research is always in progress.

Learn more biomedcentral.com/submissions 